\title{
Techno-Economic and Life Cycle Analysis of Energy Generation Using Concentrated Solar Power (CSP) Technology in Sokoto State. Nigeria
}

\author{
${ }^{1}$ SALISU, L; ${ }^{2}$ ENABUREKHAN, JS; ${ }^{* 2}$ ADAMU, AA \\ ${ }^{1}$ Department of Physical Planning, Umaru M. Yar'adua University, Katsina, Nigeria \\ ${ }^{2}$ Department of Mechanical Engineering, Bayero University, Kano, Nigeria \\ *Corresponding Author Email: aaadamu.mec@buk.edu.ng
}

\begin{abstract}
In this work a predictive performance simulation of Solar Tower, Linear Fresnel and Parabolic Trough Concentrating Solar Power (CSP) plants was undertaken for Sokoto State in Northwestern Nigeria. The State was selected based on its high Direct Normal Irradiation (DNI) values and long hours of sunshine per day relative to other places in Nigeria. The simulation was done using System Advisor Model (SAM) Software. In the study, 50 MW, 75 MW and 100 MW for each of the three CSP technologies were considered and their Techno-economic and Life Cycle analyses were carried out. The results showed that Solar Tower plant is more favored to be adopted for use in the studied site because it has the highest annual electrical energy generation, higher capacity factor and lowest Levelised cost of Electricity. The Net Present Values of the CSP plants at the site are (with the exception of the 50 MW Linear Fresnel CSP using hybrid cooling) positive implying that the project is economically viable. The study also showed that at solar multiple of 2 , the Levelised costs of Electricity for both Solar Towers and Parabolic Troughs were the lowest, irrespective of the cooling system (wet or dry cooling). Solar multiple has no effect on the water usage irrespective of the CSP plant. Dry cooling system reduces the water usage by $86 \%$ and $95 \%$ for Solar Tower and Parabolic Trough plants, respectively. Dry cooling system reduces the annual electrical energy generation in the range of 7.3 to 7.5 percent for Solar Tower plant and 8 to 9 percent for Parabolic Trough plant. The largest environmental impact was human toxicity at 25,400 g 1,4-DB eq. and the least is marine ecotoxicity at $1.33 \times 10^{-4} \mathrm{~g} 1,4-\mathrm{DB}$ eq.
\end{abstract}

DOI: DOI: https://dx.doi.org/10.4314/jasem.v23i5.1

Copyright: Copyright $\odot 2019$ Salisu et al. This is an open access article distributed under the Creative Commons Attribution License (CCL), which permits unrestricted use, distribution, and reproduction in any medium, provided the original work is properly cited.

Dates: Received: 19 April 2019; Revised: 18 May 2019; Accepted 24 May 12019

Keywords: Annual Generation; Debt Fraction; Human toxicity; Freshwater Eutrophication

Climate change is a consequence of emissions of $\mathrm{CO}_{2}$, and most of it results from burning of fossil fuels for power generation and transport sector. IEA (2008) included CSP as one of the many cost-effective technologies that will lower $\mathrm{CO}_{2}$ emissions; it also projected global energy-related $\mathrm{CO}_{2}$ emissions by 2050 to be reduced to half their 2005 level, and that CSP's are projected to produce 2,200 TWh annually by 2050 from $630 \mathrm{GW}$ of local capacities (with no exports taken in account). CSP's are also expected to contribute $5 \%$ of the annual global electricity production by 2050 in this scenario, (IEA, 2010). Habib et al., (2012) opined that the power generation capacity required to support the Nigeria Vision 20:2020 economic vision should be in the range of about $35,000 \mathrm{MW}$ of electric energy generation by 2020. They based this on the assumption that the country will take low energy intensity $(<0.4)$ growth path. Although 2020 is already at hand without the current energy production being anywhere near this figure, the need to aggressively pursue the harnessing of the nation's renewable energy resources such as solar, wind and biomass is still relevant today. The
International Renewable Energy Agency (IRENA, 2012) asserted that without access to reliable information on the relative costs and benefits of renewable energy technologies it is difficult, if not impossible, for governments to arrive at an accurate assessment of which renewable energy technologies, of which Solar (CSP) technologies are part, is the most appropriate. There is, presently, lack of adequate, comparable and up-to-date information on the costs, environmental impact and performance of Solar energy (CSP) technologies in Nigeria as such technologies have not been deployed in Nigeria. Because CSP technologies use steam Rankine power cycles that are basically the same as those used in coal and nuclear power plants and which require a cooling system to condense steam back into water in order to complete the cycle, they require one form of cooling system or the other in their operation. Though most of the water is reused in the cycle, it is still required (usually in the orders of millions of cubic meters of water, depending on the size and type of CSP technology, Bracken et al., 2015) for the cooling tower and steam cycle make-up. Three types of steam cycle 
cooling systems are used in CSP technologies: the wet-cooled (WC), dry-cooled (DC), and hybrid-cooled (HC) systems. The wet-cooled system, also called recirculating evaporative cooling, is the most commonly used and it uses a cooling tower; the drycooled system uses an air-cooled condenser; while the hybrid system incorporates both wet cooling and dry cooling systems that can be used separately or simultaneously, depending on prevailing ambient temperatures, (Bracken et al., 2015). Further, like any other industrial activity, operations of the CSP plants also generate environmental impacts that need to be identified and quantified so that they can be minimized and managed appropriately, (Corona and San Miguel, 2013).

This paper reports the technical, economic and life cycle analysis of energy generation using three technologies of concentrating solar power systems for deployment in Sokoto, North Western Nigeria.

\section{MATERIALS AND METHODS}

Materials: This study used the EnergyPlus Weather (EPW) climate files for Sokoto from Meteonorm 7 database which was uploaded into SAM software. The basic topography and ambient weather conditions (obtained from the Meteonorm software) of the study site are given in Table 1.

Table 1: Basic Topography and Meteorological Conditions of

\begin{tabular}{ll}
\multicolumn{2}{c}{ Study Site (Sokoto) } \\
\hline Parameters & Value \\
\hline Latitude $\left({ }^{\circ} \mathrm{N}\right)$ & 13.051 \\
Longitude $\left({ }^{\circ} \mathrm{E}\right)$ & 5.213 \\
Altitude $(\mathrm{m})$ & 265 \\
Annual DNI $\left(\mathrm{kWh} / \mathrm{m}^{2} /\right.$ day $)$ & 5.24 \\
Average Ambient Temperature $\left({ }^{\circ} \mathrm{C}\right)$ & 29.7 \\
Average Wind Speed $(\mathrm{m} / \mathrm{s})$ & 3.3 \\
\hline \multicolumn{2}{c}{ Source: Meteonorm V7.1.11.24422 $(2017)$}
\end{tabular}

The system/plant specifications for the three technologies considered were primarily sourced from the NREL (2017) website for Concentrating Solar Power Projects (particularly for the Andasol CSP Plant and study site conditions), Muye and Mohmmed (2015) and from SAM (2016) help contents. The market considered for this study is Independent Power Producer. The financial data for this study were compiled mainly from CBN (2017a) and CBN (2017b) - particularly for inflation rate, debt fraction, and loan/debt interest rates.

Evaluation of the Technical Performance: Simulations were carried out for each of the three technologies (Linear Fresnel, Parabolic trough and Power tower) using Wet, Dry and Hybrid cooling systems with local specific data of the selected site using the System
Advisor Model (SAM) software.

Evaluation of the Economic Aspect: Based on the annual electricity output of the simulation conducted for technical evaluation, SAM (2016) uses single year to determine the project's annual income (PPA models) or savings (distributed generation models). The performance model calculates this value by adding up the results of an hourly simulation of the system's performance over the year and the weather data and system's technical specifications from the performance model's inputs were used to determine the annual output of the system. SAM's financial models calculate a project's cash flow over an analysis period that is specified. The cash flow captures the value of electricity generated by the system and incentives, and the cost of installation, operation and maintenance, taxes and debt.

Evaluation of the Environmental Impact: Life Cycle Analysis (LCA), was carried using Umberto NXT LCA software which bases its procedure on ISO 14040:2006 and ISO 14044: 2006 Standards, and which has been tailored specifically to be used for life cycle assessment studies. The software identifies and quantifies the most impacting elements in the CSP plant and the environmental categories most impacted throughout the life cycle of the technology.

\section{RESULTS AND DISCUSSIONS}

Technical Results and Discussion: The technical performance results as generated by SAM 2011.1.17 are presented in Figures 1 to 3. The Solar Power Systems Program outlined parameters to be used for describing energy quantities for CSP systems, and their components include the total energy yield, the performance ratio, and the capacity factor. These parameters help in the comparison of similar projects to determine which works best. For this study, the total energy yield (annual electrical energy generation, AEG), the capacity factor (CF), Land (Area) requirement, and the annual water usage/consumption were used (AWU) to analyse the performance of the CSP technologies considered.

Annual Electrical Energy Generation: From Figures 1, 2 and 3, it is observed that, for a turbine capacity of 50-MW CSP using wet cooling system, the Solar Tower technology generates the highest annual energy of $177 \mathrm{GWh}$ followed by Parabolic Trough with 146.2 GWh; for the 75-MW CSP with the same system of cooling, the Parabolic Trough with 216.4 GWh generates the highest followed by Solar Tower with 157.6 GWh; while for the 100-MW CSP with wet cooling system, the Parabolic Trough technology generates the highest with 288.1 GWh using wet 
cooling system followed by Linear Fresnel with 152.4 GWh.

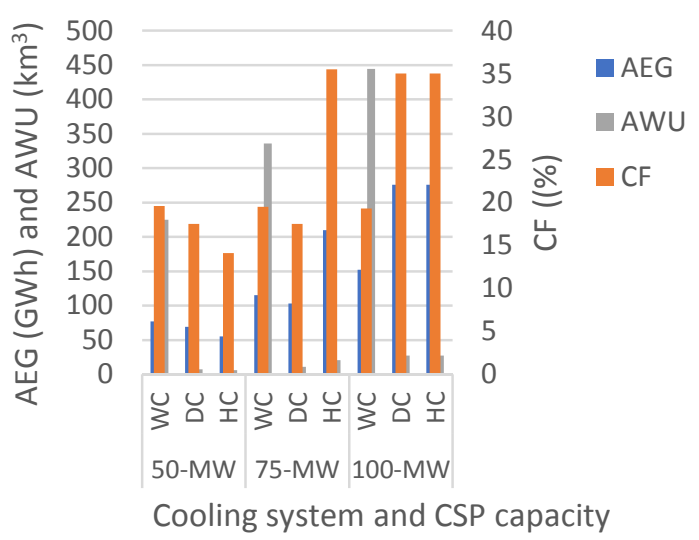

Fig 1: Technical results for the Linear Fresnel CSP Technology

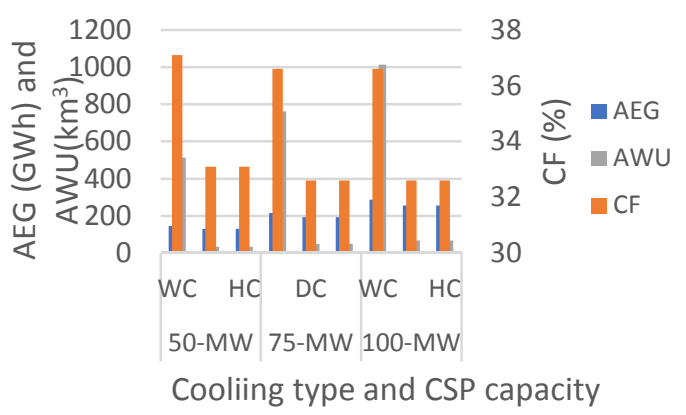

Fig 2: Technical results for the Parabolic Trough CSP Technology

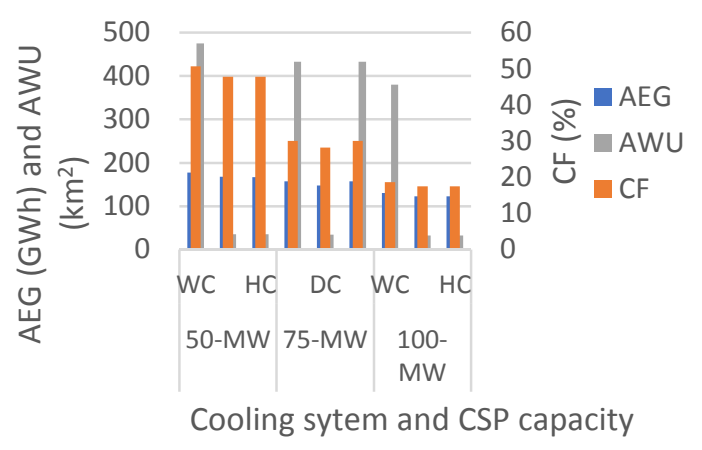

Fig 3: Technical results for the Solar Tower CSP Technology

Effect of Cooling System and Solar Multiple: In an attempt to evaluate how the annual electrical energy generation of CSP technology values vary with technology configuration, a range of configuration parameters, such as cooling system, and solar multiple (SM) were considered. In the process of generating electricity, waste heat has to be removed and/or rejected somehow to the environment. The vast majority of heat removal and/or rejection are through cooling system. The end result of the condensation is lowering of the steam temperature at the turbine outlet (sink temperature), which will in general increase the cycle efficiency. The cooling or condensation of the steam can be provided via water-cooling, air-cooling, or a combination. These three categories of CSP plant cooling system are generally referred to as wet, dry, and hybrid.

In this work, effects of replacing wet cooling (WC) system with dry (DC) or Hybrid cooling (HC) system and variation of solar multiple on the annual electrical energy generation of Solar Tower, Linear Fresnel and Parabolic Trough CSP technologies has been studied with the hour of thermal energy storage being fixed at 8 hours.

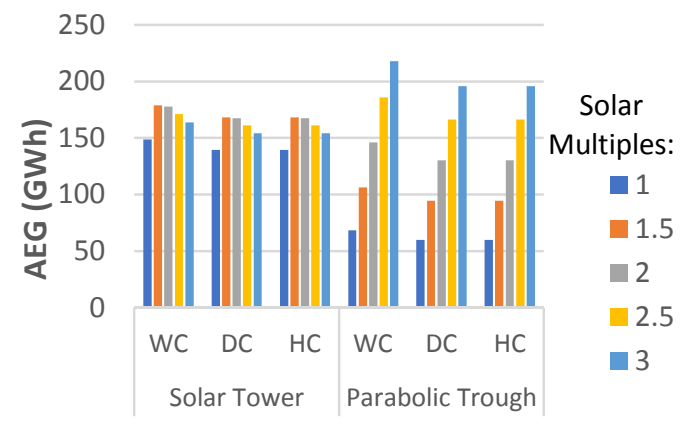

Cooling system and CSP configuration

Fig 4: Effect of cooling system and solar multiples on annual energy production

From Figure 4, it can be seen that for the same value of solar multiple, annual electrical energy generation of Solar Tower CSP technology is higher than that of Parabolic Trough CSP technology irrespective of the cooling system. However, at different values of solar multiple, the employment of dry cooling system in place of the evaporative wet cooling system results in the annual electrical energy generation penalization irrespective of the CSP technology. The penalization is in the range of 5.8 to 6.3 percent for Solar Tower CSP technology and for Parabolic Trough CSP technology it is between 10.2 to 12 percent. The reason for the annual electrical energy reduction lies primarily on the inherent underperformance of dry cooling systems in high temperatures and secondly on the additional auxiliary power requirements introduced by the dry cooling system condenser (e.g., fans).

There is also a noticeable increase in the annual electrical energy generation of Solar Tower CSP technology between solar multiple of 1 and 1.5 irrespective of the cooling system. But beyond solar 
multiple of 1.5, the annual electrical energy generation of Solar Tower CSP technology begins to decrease gradually. This implies that at solar multiple of 1.5, Solar Tower CSP technology will store and deliver more of the excess heat from the solar field to the power block resulting in higher capacity factor and subsequently higher generation of annual electrical energy. On the other hand, a continuous increase of the annual electrical energy generation of Parabolic Trough CSP technology with increase in solar multiple is noticed. This implies that the higher the solar multiple, the higher the annual electrical energy generation from the Parabolic Trough CSP technology.

Annual Water Usage: Because, CSP plants require lager volumes of water in their operation, the availability of water can pose serious challenges to their deployment. According to Poullikkas et al., (2013), the cost of water and of water transportation (in relation to the distance of the CSP plant from the water source) can play an important role in the estimation of overall CSP plant economics and can tilt the balance in the decision of which cooling technology to be adopted. They further added that CSP plant permits, plans and cooling processes rely on access to and planned use of water. Therefore, cooling system and solar multiple effects on CSP plant water usage was studied in this work.

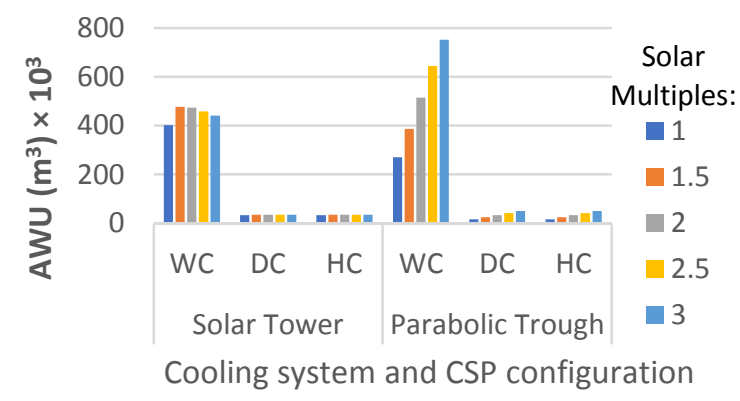

Fig 5: Effect of Cooling system and solar multiples on annual water usage

CSP plant water usage when wet cooling system is used instead of the dry or Hybrid cooling system irrespective of the CSP technology is profound at each solar multiple value. Figure 5 shows that there is $91.7 \%$ and $96.6 \%$ reduction of annual water usage (AWU) when wet cooling system is replaced with dry or Hybrid cooling system for the Solar Tower and Parabolic Trough CSP technologies respectively. This trend of reduction in annual water usage between the cooling systems of the CSP technologies is also noticed for other solar multiple values. This is in agreement with the assertion of Poullikkas et al.,
(2013) that the use of dry cooling system instead of evaporative wet cooling system reduces the CSP technology annual water usage by as much as $90 \%$. As a consequence of this large reduction in water usage, reductions in overall plant investment and in electricity unit costs can thus be expected if dry cooling system is used. Poullikkas et al., (2013) further stated that, depending on the cost of water, the reduction in electricity unit cost may prove to be important in terms of financial viability of the CSP plant.

Capacity Factor: Capacity factor is the number of hours per year (expressed as a percentage) that Concentrated Solar Power plant can produce electricity. From Figures 1 to 3, it is clear that, Solar Tower CSP plant has the highest number of hours per year of electricity generation with a capacity factor (CF) of $50.7 \%$ (or about 4,441 thousand hours out of 8,760 hours in a year) followed by Parabolic Trough with $37.1 \%$ (about 3,250 hours).

Figure 6 on the other hand, shows the effect cooling system and solar multiples on the capacity factor for the two technologies with the highest capacity factors (Solar Tower and Parabolic Trough). It is noticed that the wet cooling system, again, gives the highest values of capacity factor at $55.3 \%$ at solar multiple of 3 for the Parabolic Trough CSP, while the second highest is now for the Solar Tower CSP with $51 \%$ and solar multiple of 1.5. However, in the case of the former, the significantly higher value in capacity factor shall have some significant financial implication for the higher value of solar multiple.

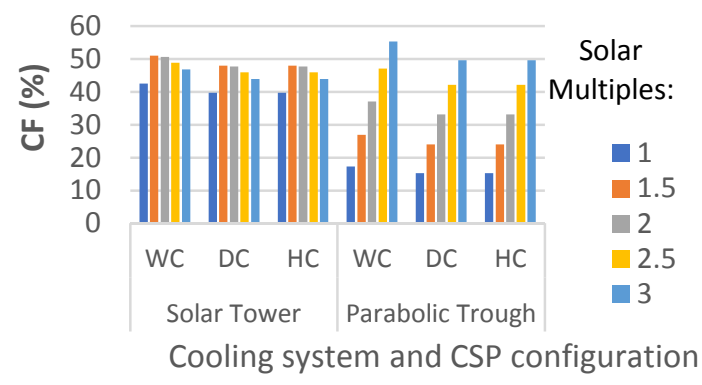

Fig 6: Effect of cooling system and solar multiples on capacity factor

Effect of Cooling System and Duration of Thermal Storage on Annual Energy Generation: The effect of the cooling system and duration of thermal storage on annual energy generation was also investigated for the Solar Tower and the Parabolic Trough CSP's. Figure 7 shows that in the case of the Solar Tower CSP, the wet cooling yielded the highest annual energy 
generation while the duration of thermal storage had no significant impact on the annual energy generation. In the case of the Parabolic Trough CSP, however, dry and hybrid cooling systems gave the highest annual energy generation with little or no difference among them. There are, however, significant differences in the amount of annual energy generation between the wet cooling system and other cooling systems for the Solar Tower CSP on the one hand and between the dry and hybrid cooling system and the wet cooling system for the Parabolic Trough CSP on the other hand.

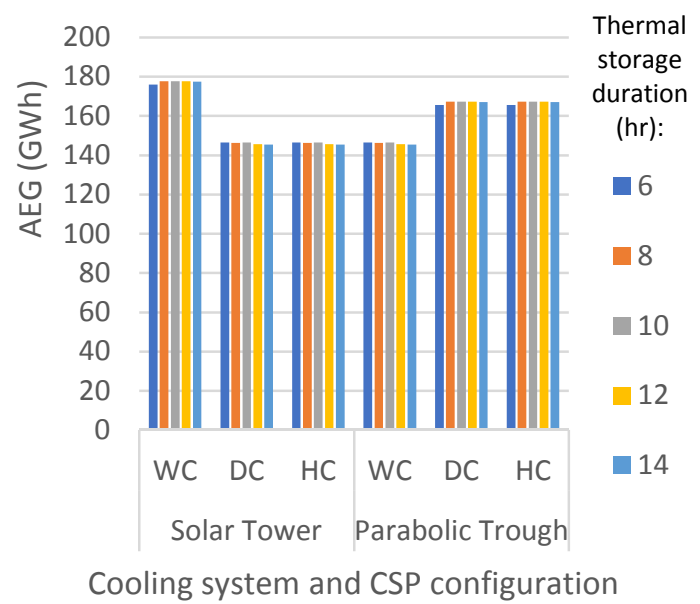

Fig 7: Effect of duration of thermal energy storage and cooling system on annual electric energy generation

Financial Results and Discussion: The financial results as generated by SAM 2017.1.17 are presented in Figures 8 to 10 for the studied site.

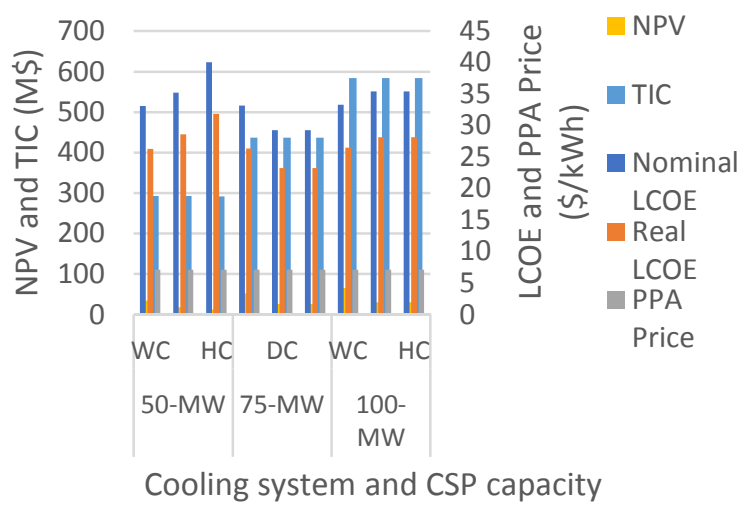

Fig 8: Economic analysis results for the Linear Fresnel CSP Technology

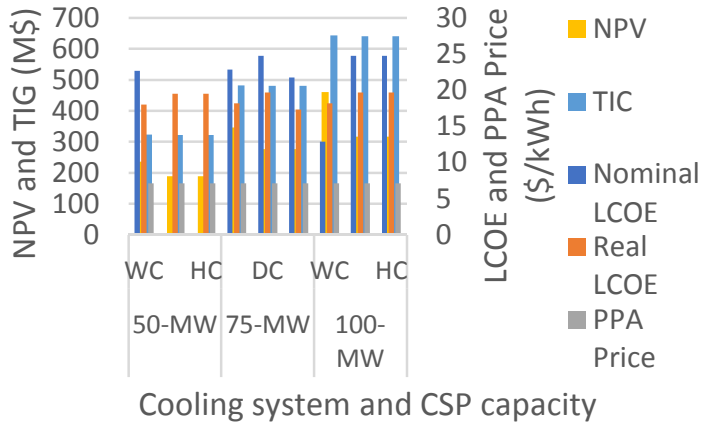

Fig 9: Economic analysis results for the Parabolic Trough CSP Technology

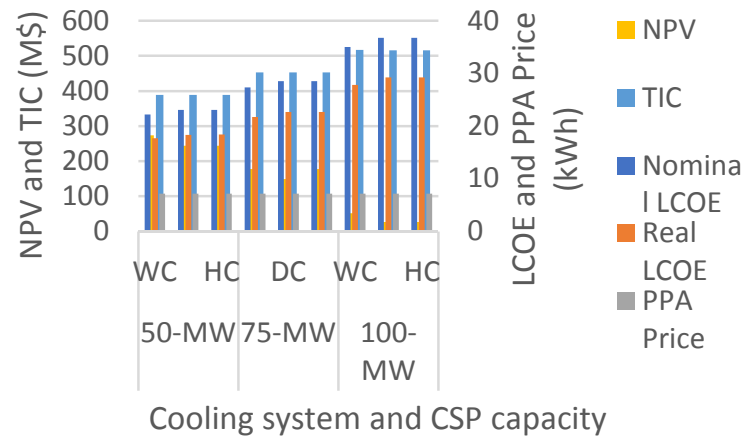

Fig 10: Economic analysis results for the Solar Tower CSP Technology

Levelised Cost of Electricity: The Levelised Cost of Electricity (LCOE), an economic assessment of the cost of energy from a generating system, is the price at which electricity must be generated from a specific source in order to break even over the lifetime of the project. The real LCOE, rather than the nominal one, is more appropriate for use here since analysis is based on long-term situation. For Sokoto, the Linear Fresnel CSP has the highest value of real LCOE at 26.33 Cent/kWh (or $96.10 \$ / \mathrm{kWh}$, at $\$ 365$ to $1 \$$ ); this is followed by the Parabolic Trough CSP with 18.04 Cent/kWh (or $65.85 \mathrm{NWh}$ ); and the least is the Solar Tower CSP with 17.71 Cent/kWh (equivalent to 64.64 \#/kWh).

The effect of cooling system and solar multiple on the Levelised Cost of Electricity, for the CSP technologies with the least LCOE, is depicted in Figure 11. 


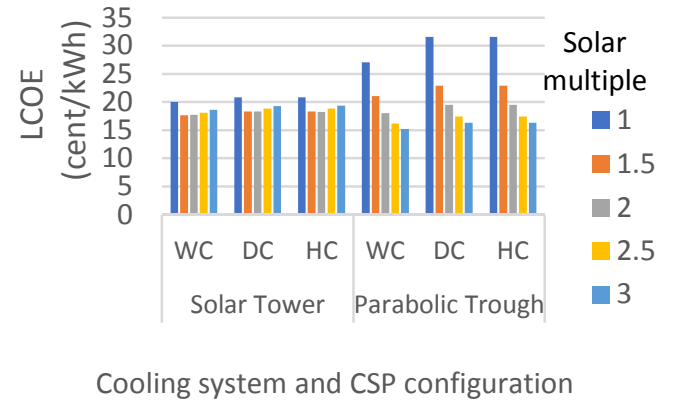

Fig 11: Effect of Cooling system and Solar Multiples on Levelised Cost of Electricity

For both CSP technologies, the wet cooling gave the least values of real LCOE; at $17.71 \mathrm{Cent} / \mathrm{kWh}$ and solar multiple of 2 for the Solar Tower CSP and at 15.24 Cent $/ \mathrm{kWh}$ (or $55.63 \mathrm{~N} / \mathrm{kWh}$ ) for the Parabolic Trough at solar multiple of 3 . If low LCOE is a key policy for deployment, then solar multiple of 1 and both dry and hybrid cooling systems must be avoided for the two CSP technologies. These combinations gave values of LCOE of 20.85 Cents/kWh $(76.10$ $\mathrm{N} / \mathrm{kWh}$ ) for the Solar Tower CSP and $31.54 \mathrm{Cent} / \mathrm{kWh}$ $(115.12 \mathrm{NWh})$ for the Parabolic Trough CSP.

Net Present Value (NPV) and Total Cost of Installation (TIC): The Net Present Value (NPV) of a project is the total present value of a time series of cash flow of the project; it is the difference between the discounted cash flows (inflow and outflow) of the project. It is a method used to determine the current value of all future cash flows generated by a project, including the initial capital investment, (Jagerson, 2018).

From Figures 8 to 10, the wet cooling system for the 100-MW Parabolic Trough CSP has the highest value of NPV of about $\$ 461.05$ million (or about $\$ 168.28$ trillion). The least positive value of NPV (of $\$ 17.65$ million or $\$ 6.44$ trillion) was obtained for the 50-MW dry-cooled Linear Fresnel CSP. Since the values of NPV are all positive (except that of the $50 \mathrm{MW}$ hybridcooled Linear Fresnel CSP which is negative) then CSP technologies are economically viable for Sokoto. Comparatively, the wet-cooled Parabolic Trough CSP is the most economically viable for Sokoto; it also has the highest values of NPV for dry and hybrid cooling systems (each at \$316.34 million or \$115.47 trillion). However, they also have the highest total installation cost (TIC) of about $\$ 643.90$ million or about $\$ 235$ trillion. A good compromise would then be to consider the 50-MW Solar Tower CSP technology with wet cooling system and having a value of NPV of about $\$ 273.87$ million or about \$99.96 trillion and total cost of installation of about $\$ 389.15$ million or about $\$ 142.04$ trillion.

Environmental and Life Cycle Analysis Results and Discussion: Table 2 shows the characterised environmental impacts using the solar tower $50 \mathrm{MW}$ CSP plant with wet cooling system for Sokoto.

Table 2: Characterized impacts of the CSP plant per impact category and life phase in Sokoto

\begin{tabular}{llllll}
\hline Impact Category & Units (per MWh) & $\begin{array}{l}\mathbf{E}, \mathbf{M} \& \mathbf{C} \\
\times \mathbf{1 0}^{-5}\end{array}$ & $\mathbf{O ~ \& ~ M}$ & $\begin{array}{l}\mathbf{D} \& \mathbf{D} \times \\
\mathbf{1 0}^{-\mathbf{0 5}}\end{array}$ & Total \\
\hline Climate Change & $\mathrm{kg} \mathrm{CO}$ eq. & 117 & 12.2 & 117 & 12.2023 \\
Terrestrial Acidification & $\mathrm{g} \mathrm{SO}_{2}$ eq. & 2.8 & $56 \times 10^{-5}$ & 2.8 & $61.6 \times 10^{-5}$ \\
Freshwater Eutrophication & $\mathrm{g} \mathrm{P}$ eq. & 0.25 & $79.9 \times 10^{-5}$ & 25 & $80.4 \times 10^{-5}$ \\
Human Toxicity & $\mathrm{kg}$ 1.4-DB eq. & 4.1 & 25.4 & 4.1 & 25.4000 \\
Freshwater Ecotoxicity & $\mathrm{g}$ 1.4-DB eq. & 0.09 & $62.2 \times 10^{-5}$ & 0.09 & $62.3 \times 10^{-5}$ \\
Marine Ecotoxicity & $\mathrm{g}$ 1.4-DB eq. & 0.01 & $13.3 \times 10^{-5}$ & 0.01 & $13.3 \times 10^{-5}$ \\
\hline
\end{tabular}

Key: E, M \& C: Extraction, Manufacture and Construction; O \& M: Operation and Maintenance; and D \& D: Dismantling and Decommissioning.

Table 2 shows that the most impacted phase in the life cycle of the CSP technology is the operation and maintenance, as the metrics show significantly larger values than the corresponding ones for the extraction, manufacture and construction and for the dismantling and decommissioning phases. This is in line with the findings of Corona and San Miguel (2013).

The characterized LCA metric, human toxicity showed the greatest environmental impact for the reference CSP at a value of $25.4 \mathrm{~kg} 1,4-\mathrm{DB}$ eq/MWh from cradle to grave. It is, however, still lower than some from literature, as indicated in Table 3. All the metrics in Table 3 have the same unit with the corresponding ones in Table 2 (those not initially so have been converted to this).

Other metrics that have some corroboration with those in literature are the terrestrial acidification with a value of $61.6 \times 10^{-5} \mathrm{~g} \mathrm{SO}_{2} \mathrm{eq} / \mathrm{MWh}$ and climate change of $12.2 \mathrm{~kg} \mathrm{CO} 2$ eq/MWh. 
Table 3: Comparison of the Reference CSP with others from literature (cradle to grave)

\begin{tabular}{|c|c|c|c|c|c|}
\hline Impact Category & $\begin{array}{l}\text { Reference } \\
\text { Plant }\end{array}$ & $\begin{array}{l}\text { Mazzaferro } \\
(2017)\end{array}$ & $\begin{array}{l}\text { Corona, et al., } \\
(2016)\end{array}$ & $\begin{array}{l}\text { Corona and San Miguel } \\
(2014) ; \mathrm{CSP}+12 \% \text { Nat. gas }\end{array}$ & $\begin{array}{l}\text { Corona and San Miguel } \\
\text { (2014); solar only }\end{array}$ \\
\hline Climate Change & 12.20234 & 25.9 & 45.9 & 125 & 26.9 \\
\hline $\begin{array}{l}\text { Terrestrial } \\
\text { Acidification }\end{array}$ & 0.000616 & 0.000134 & 509 & 216 & 168.0 \\
\hline $\begin{array}{l}\text { Freshwater } \\
\text { Eutrophication }\end{array}$ & 0.000804 & 0.0000473 & 16.9 & 9.4 & 10.0 \\
\hline Human Toxicity & 25.400082 & 84.6 & 27.5 & 12.1 & 13.0 \\
\hline $\begin{array}{l}\text { Freshwater } \\
\text { Ecotoxicity }\end{array}$ & 0.0006238 & 0.0178 & 1033 & 306 & 329.0 \\
\hline Marine Ecotoxicity & 0.0001332 & 32.8 & 1028 & 324 & 340.0 \\
\hline
\end{tabular}

The least impact metric was found to be marine ecotoxicity at $13.3 \times 10^{-5} \mathrm{~g} \mathrm{1,4-DB}$ eq/MWh and was found to be very much less than the equivalent ones from literature. Other metrics outside those found in literature include those of freshwater ecotoxicity, and freshwater eutrophication. This may be explained by the fact that the location of the plant has a significant influence on the LCA results, (Mazzaferro, 2017).

Conclusion: Although all three CSP technologies studied have acceptable values of techno-economic and environmental impact over their life cycles, the Solar Tower CSP with the highest techno-economic indices, is the technology that is most favoured to be adopted for use in the study site.

\section{REFERENCES}

Bracken, N; Macknick, J; Tovar-Hastings, A; Komor, P; Gerritsen, M; Mehta, S. (2015). Concentrating Solar Power and Water Issues in the U.S. Southwest. Technical Report: NREL/TP-6A5061376, Joint Institute for Strategic Energy Analysis (JISEA), Denver, USA.

CBN, Central Bank of Nigeria (2017a). https://www.cbn.gov.ng/rates/. Accessed April, 2017.

CBN, Central Bank of Nigeria (2017b).

www.tradingeconomics.com/nigeria/interest-rate. Accessed April, 2017.

Corona, B; San Miguel, G (2013). Environmental Assessment of Concentrating Solar Power (CSP) Technology Using LCA. Proceedings of the 13th International Conference on Environmental Science and Technology Athens, Greece, 5-7 September, 2013. Pp $1-6$.

Corona, B; San Miguel, G (2014). Environmental Analysis of Concentrated Solar Power (CSP) Plant Hybridised with Different Fossil and
Renewable Fuels. Sci. Tech. Fuel and Energy, Elsevier. Pp $63-69$.

Corona, B; Ruiz, D; San Miguel G (2016). Life Cycle Assessment of a HYSOL Concentrated Solar Power Plant: Analyzing the Effect of Geographic Location. energies, pp 1 - 14. www.mdpi.com/journal/energies. Accessed May, 2018.

Habib, SL; Idris, NA; Ladan, MJ; Mohammad, AG (2012). Unlocking Nigeria's Solar PV and CSP Potentials for Sustainable Electricity Development. Int. J. of Sc. and Eng. Resch (IJSER). Volume 3, pp $1-8$.

IEA (2008). Energy Technology Perspectives. International Energy Agency/Organization for Economic Cooperation and Development, OECD/IEA, Paris, France.

IEA (2010). Technology Roadmap: Concentrating Solar Power. International Energy Agency/Organization for Economic Cooperation and Development, OECD/IEA, Paris, France.

IRENA (2012). Renewable Energy Technologies: Cost Analysis Series. Volume 1: Power Sector Issue 3/5. International Renewable Energy Agency.

Jagerson, J (2018). Net Present Value. https://www.investopedia.com/contributors/93/. Accessed $2^{\text {nd }}$ January, 2019,

Mazzaferro, CA (2017). Life Cycle Assessment of Electricity Production from Concentrating Solar Thermal Power Plants. PhD Thesis, Department of Industrial Engineering, University of Padova, Italy.

Meteonorm V7.1.11.24422 (2017). Metrological Data. http://www.meteonorm.com/en/site/ 
downloads/? /download/software/. Accessed May, 2017.

Muye, H; Aliyu, G; Mohammed, K (2015). Comparative Study of Solar Tower and Parabolic Trough Concentrated Solar Power Technologies in Kano, Northern Nigeria. The Int. J. of Sc. and Tech. Vol3(10). Pp 176 - 183.

NREL (2017). Concentrating Solar Power Projects.

National Renewable Energy Laboratory https://solarpaces.nrel.gov/. $\quad$ Accessed January,2017
Poullikkas, A; Hadjipaschalis, I; Kourtis, G (2013). A Comparative Overview of Wet and Dry Cooling Systems for Rankine Cycle Based CSP Plants. Trends in Heat and Mass Transfer. Vol. 13, pp 1 -25 .

SAM (2016). SAM Help. System Advisor Model 2011.1.17 - www.nrel.sam/help Accessed February, 2016. 